\section{Slipshod approvals taint Japanese animal studies}

David Cyranoski, Tokyo

Animal-welfare campaigners have revealed irregularities in the way that animal experiments are approved in Japan.

The Tokyo-based Anti-Vivisection Action Network says one researcher was able to approve his own application for a project. Another application stated that 63 animals would be used, but failed to state what kind of animals were involved. "It's hard to tell whether anyone is really looking at these," says Fusako Nogami, director of the network.

The findings, taken from an initial analysis of research proposals for more than 1,000 experiments approved by 19 publicly funded research organizations, were presented to the environment ministry on 4 August. The ministry, which is holding monthly meetings on animal welfare in the run-up to an expected revision of animal-protection laws next year, says the cases could be procedural errors and do not mean that animals are being maltreated.

But Nogami says that laxity in the system could obscure abuses in labs. She wants the government to establish rules like those used in Europe and North America, where laboratories that do animal research are required to register with a government-approved body. She is also pressing for enforceable laws and an external watchdog. The section of the current animal-protection law that deals with research includes neither a penalty for offenders nor a mechanism for enforcement.

Researchers who work with animals deny Nogami's claims about possible abuses, insisting that they stick to high welfare standards that are well regulated by their institutions. But the Science Council of Japan, which represents some 1,500 scientific and academic societies, recognizes that legislation needs to be tightened up. In a report issued on 15 July, the council recommended the creation of national guidelines and an external evaluation system to ensure that they are implemented.

The environment ministry is sceptical about the proposal. A spokesperson pointed out that the research section of the animal-protection law can only be changed with the agreement of the education, health and environment ministries - a tricky feat for Japan's bureaucratic government. "It would be very difficult," says the spokesperson.

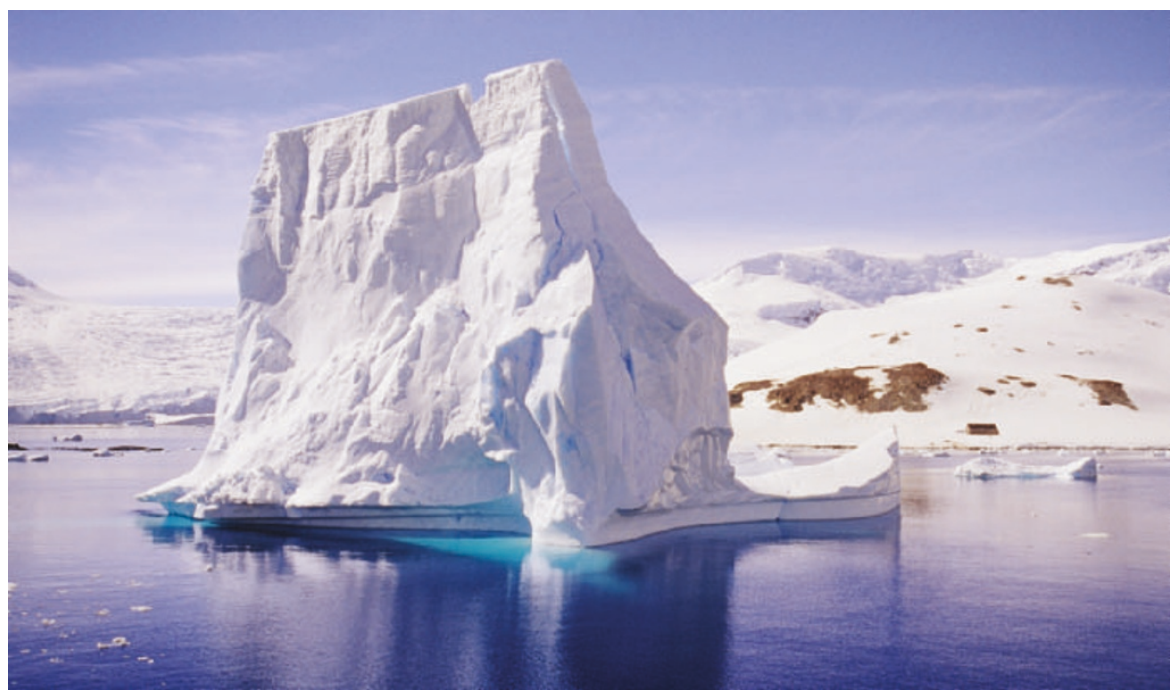

Free for all: the Antarctic Treaty cannot protect the frozen continent from bioprospectors.

\title{
Stiffer rules required to stop commerce milking Antarctica
}

\section{Emma Marris}

The Antarctic could be damaged by unregulated commercial research unless the laws covering the area are updated, polar scientists have warned.

The South Pole is governed by the Antarctic Treaty on principles of peace, openness and international cooperation more free love than free enterprise. The agreement says nothing about how the area's flora and fauna can be exploited, prompting delegates at last month's meeting of the Scientific Committee on Antarctic Research to call on politicians to rethink the treaty.

Researchers who attended the conference, held in Bremen, Germany, from 25 to 31 July, said that commercial companies are taking an increasing interest in Antarctica. Organisms at the pole must employ complex strategies to survive, such as using antifreeze molecules to keep their insides fluid in subzero temperatures. Over the past five years, several patents have been granted on these and other potentially useful substances.

But such patents are not governed by the treaty, which states only that any scientific findings should be "freely available". Some fear that companies may patent an organism and prevent other scientists from working with it. "That would turn around and bite basic research," says John Priscu, a microbiologist from Montana State University in Bozeman, who attended the Bremen meeting. "It's a last frontier down there and we don't want to lock up its secrets."

The Antarctic scientific committee, which provides advice to the 45 nations that have ratified the Antarctic Treaty, cannot rewrite the rules. But Priscu says he plans to press the matter when the treaty nations meet next summer, and he has the support of David Walton, head of the environment and information division at the British Antarctic Survey in Cambridge, UK. Before then, Priscu and Walton will draft a report on the potential scientific consequences of intense bioprospecting.

Besides the problem of patents, they worry that harvesting samples could do ecological damage. Antarctic organisms are particularly vulnerable, because they grow so slowly. Priscu studies the mats of microbes that grow on the floors of iced over lakes. These are the old-growth forests of Antarctica - it may take them up to a decade to double their size - yet researchers haul them off by the bagful for sampling. "I am concerned that these fragile mats are being destroyed," says Priscu. He plans to recommend a census of all biological material collected, by weight and area, which may encourage limits to be set.

This is not the first time researchers have warned of the dangers of bioprospecting in Antarctica. At last year's meeting of Antarctic Treaty states, the committee saw a report from the United Nations University in Tokyo that warned of a "free-for-all" and a "goldrush" mentality if rules were not put in place. But no action was taken.

The most obvious answer, say many polar researchers, would be to adapt the guidelines of the UN Convention on Biological Diversity, which is designed to ensure that countries undertake bioprospecting in a sustainable fashion. But Walton points out that following such ready-made rules may not be possible; the United States has not ratified the convention and may refuse to abide by it in the Antarctic. 